\title{
Prevalence of single and multiple infection with human papillomaviruses in various grades of cervical neoplasia
}

\author{
D. Y. CHANG, R. J. CHEN, S. C. LEE* and S. C. HUANG \\ Department of Obstetrics and Gynecology, *Institute of Molecular Medicine, College of Medicine and \\ Hospital, National Taiwan University, Taipei, Taiwan
}

\begin{abstract}
Evaluation of human papillomavirus (HPV) diversity in various grades of cervical lesions is helpful for understanding the characteristics of HPV infection in the pathogenesis of cervical neoplasia. A total of 227 women with normal cervices $(n=72)$, low- and high-grade cervical squamous intraepithelial lesions (SILs) $(n=55$ and 53, respectively) and cervical carcinomas $(n=47)$ were screened for human papillomavirus (HPV) types 6, 11, 16 and 18 infection by the polymerase chain reaction. The prevalence of multiple HPV infections in patients with normal cervices, low-grade SILs, high-grade SILs and cervical carcinomas was $22.2 \%, 61.8 \%, 41.5 \%$ and $21.3 \%$, respectively, while the prevalence of a single-type infection was $36.1 \%, 21.8 \%, 30.2 \%$ and $61.7 \%$, respectively. HPV $16 / 11$ and $16 / 18$ were the most common combinations observed in multiple infections. Multiple HPV infections were seen most frequently in patients with low-grade SILs, and the prevalence decreased with increasing severity of cervical neoplasia. In contrast, infection with a single HPV type was most commonly observed in patients with cervical carcinoma, and the prevalence decreased with decreasing severity of cervical neoplasia. HPV 16 was the predominant single-type infection in patients with cervical carcinoma and this prevalence decreased steadily with decreasing severity of cervical neoplasia. Conversely, HPV 11 was the predominant single-type infection in patients with normal cervices. This prevalence decreased with increasing severity of cervical neoplasia. Patients with low-grade SILs had a higher prevalence of HPVs, regardless of single or multiple infection status, and larger copy numbers of virus genome were seen more frequently in patients with more severe lesions.
\end{abstract}

\section{Introduction}

Human papillomaviruses (HPVs) are known to be associated with cervical neoplasms. More than $60 \mathrm{HPV}$ genotypes have been characterised and at least 22 genotypes have been indentified in genital tract infection [1,2]. Among them, HPV types 6 and 11 are commonly associated with benign lesions such as condylomata acuminata, whereas types 16 and 18 are more frequently associated with cervical malignancy [3-5]. In-vitro studies of HPV types 6 and 11 have indicated that they do not share the oncogenic potential of HPV 16 and 18 but, occasionally, HPV 6 and 11 may be found in some malignant lesions [6].

Cervical neoplasia, including squamous intra-epithelial lesions (SILs) and cervical cancer, represent a group

Received 18 Jan. 1996; revised version accepted 5 June 1996.

Corresponding author: Dr S. C. Huang. of heterogeneous diseases from a virological viewpoint $[7,8]$. There is considerable variation in the prevalence of HPV infection within each lesion group. Women with cervical cancer have HPV types 16 and 18 infection more frequently than women with normal cervices [9]. The prevalence of HPV types 16 and 18 increases with increasing severity of cervical neoplasia [10]. Conversely, HPV types 6 and 11 are seldom found in cervical cancer but appear to be more frequent in SILs than in normal cervices [11]. The management of patients with HPV infection may be influenced by the infecting HPV type as well as by routine histological examination of the lesions [12]. Evaluation of HPV diversity in various grades of cervical lesions is helpful for understanding the characteristics of HPV infection in the pathogenesis of cervical neoplasia.

The polymerase chain reaction (PCR) has been used recently to detect trace amounts of DNA in samples with great sensitivity [13]. The PCR can detect HPV 
sequences from tissues that give negative results by Southern blot hybridisation [14-17]. Hence, more cases with small copy numbers of HPV DNA, such as those with latent or subclinical infection, become detectable by PCR. The epidemiological data of HPV infection obtained by applying the PCR will be different from that obtained by other conventional hybridisation methods. As the use of PCR increases, reports of multiple infections will be more common. The interactions between different types of HPV during the progression of cervical neoplasia can also be studied. By using type-specific primers and two steps of PCR, the present work attempted to clarify the prevalence of cervical HPV types $6,11,16$ or 18 infection, either single or multiple, among patients with various grades of cervical neoplasia.

\section{Materials and methods}

\section{Subjects and specimens}

Four groups of patients were studied. Group A $(n=72)$ comprised patients with normal cervices (aged 16-65, mean 38.0 years). Group $B(n=55)$ were patients with low-grade SILs (aged 25-66, mean 41.2 years). Group $\mathrm{C}(\mathrm{n}=53)$ were patients with high-grade SILs (aged 25-62, mean 41.2 years). Group $D(n=47)$ were patients with cervical carcinomas (aged 32-69, mean 51.5 years). Patients with cervical carcinomas were significantly older than patients with normal cervices or cervical SILs $(p<0.001)$. Most cases came from the out-patient or colposcopy clinic, but some cases of cervical carcinoma were collected from ward patients before radical operation or radiotherapy. The diagnoses were based on the pathological reports of cervical biopsy samples. Patients with normal cervices had negative cervical pathology in addition to normal Papanicolaou smear results and colposcopic findings. The target DNA was extracted from cells of repeated cervical scraping by a phenol-chloroform-ethanol method, and the concentrations of DNA in the samples were determined by spectrophotometry [18].

\section{Oligonucleotide primers}

The primers for HPV 6, 11, 16 and 18 detection were synthesised by a DNA synthesiser (Model 381A,
Applied Biosystems Inc., CA, USA) and purified by oligonucleotide purification cartridges (Applied Biosystems). All the primers were derived from the most conserved E6 or regulatory region of the HPV genome [19]. The sequences of the primers are shown in Table 1.

\section{PCR}

The PCR was done as described previously [14]. Briefly, cellular genomic DNA (500 ng) and purified HPV DNA (100 pg, positive control) were amplified in a reaction mixture $(100 \mu \mathrm{l})$ containing: PCR buffer, primer mix, deoxynucleoside triphosphate mix and Taq DNA polymerase. Salmon sperm DNA (500 ng) was used as the negative control and reaction mixture without genomic DNA was used as the blank. Amplification was performed with an automated thermal cycler (Perkin-Elmer Cetus, USA) with denaturing conditions of $95^{\circ} \mathrm{C}$ for $2 \mathrm{~min}$, followed by 35 cycles of $94^{\circ} \mathrm{C}, 55^{\circ} \mathrm{C}$ and $72^{\circ} \mathrm{C}$ for $1 \mathrm{~min}$ each, and a final extension at $72^{\circ} \mathrm{C}$ for $10 \mathrm{~min}$. After the first-step PCR, a portion $(10 \mu \mathrm{l})$ of the reaction mixture was used as the source of target DNA in the second-step PCR for further amplification. To avoid contamination, the PCR was prepared in a hood restricted to this purpose. There was overnight treatment of laminar flow and ultraviolet irradiation in the hood between each PCR run. The sensitivity of PCR was tested with serial dilutions of a known concentration of standard HPV DNA. As little as $10^{-2} \mathrm{pg}$ of standard HPV DNA could be detected at the end of the first-step PCR. The sensitivity increased to $10^{-7} \mathrm{pg}$ of standard HPV DNA after two step PCR.

After each step of the PCR, the reaction mixtures were tested for positive signals by gel electrophoresis (Fig. 1) and dot-blot hybridisation (Fig. 2) [14]. Only those samples that gave the correct bands on electrophoresis and hybridisation signals were interpreted as positive for HPV infection. Patients with positive results by the first-step and by two steps of PCR were recorded and analysed separately.

Student's $t$ test and cross-table $\chi^{2}$ test were used for statistical analysis. A p value $>0.01$ was considered to be non-significant.

Table 1. Primer sequences of HPV types 6,11,16 and 18 used in the PCR

\begin{tabular}{lllcc}
\hline HPV type & & $5^{\prime} \rightarrow 3^{\prime}$ nucleotide sequence & Genomic site & $\begin{array}{c}\text { Fragment } \\
\text { size }(\mathrm{bp})\end{array}$ \\
\hline 6 & 1R & AGACCAGTTG TGCAAGACGT TTAA & $140-163$ & 263 \\
& 1L & GCACGTCTAA GATGTCTTGT TTAG & $402-379$ & \\
11 & $1 \mathrm{R}$ & CATCTATAGA CCAGTTGTGC AAGA & $133-156$ & 406 \\
& $1 \mathrm{~L}$ & TCCATGCATG TTGTCCAGCA GTGT & $538-515$ & \\
16 & 1R & ACTGCACATG GGTGTGTGCA AACC & $7836-7859$ & 694 \\
& 1L & GATCAGTTGT CTCTGGTTGC AAAT & $625-602$ & \\
18 & 1R & CACACCACAA TACTATGGCG CGCT & $91-114$ & 472 \\
& 1L & CGTCGTTGGA GTCGTTCCTG & $562-543$ & \\
\hline
\end{tabular}




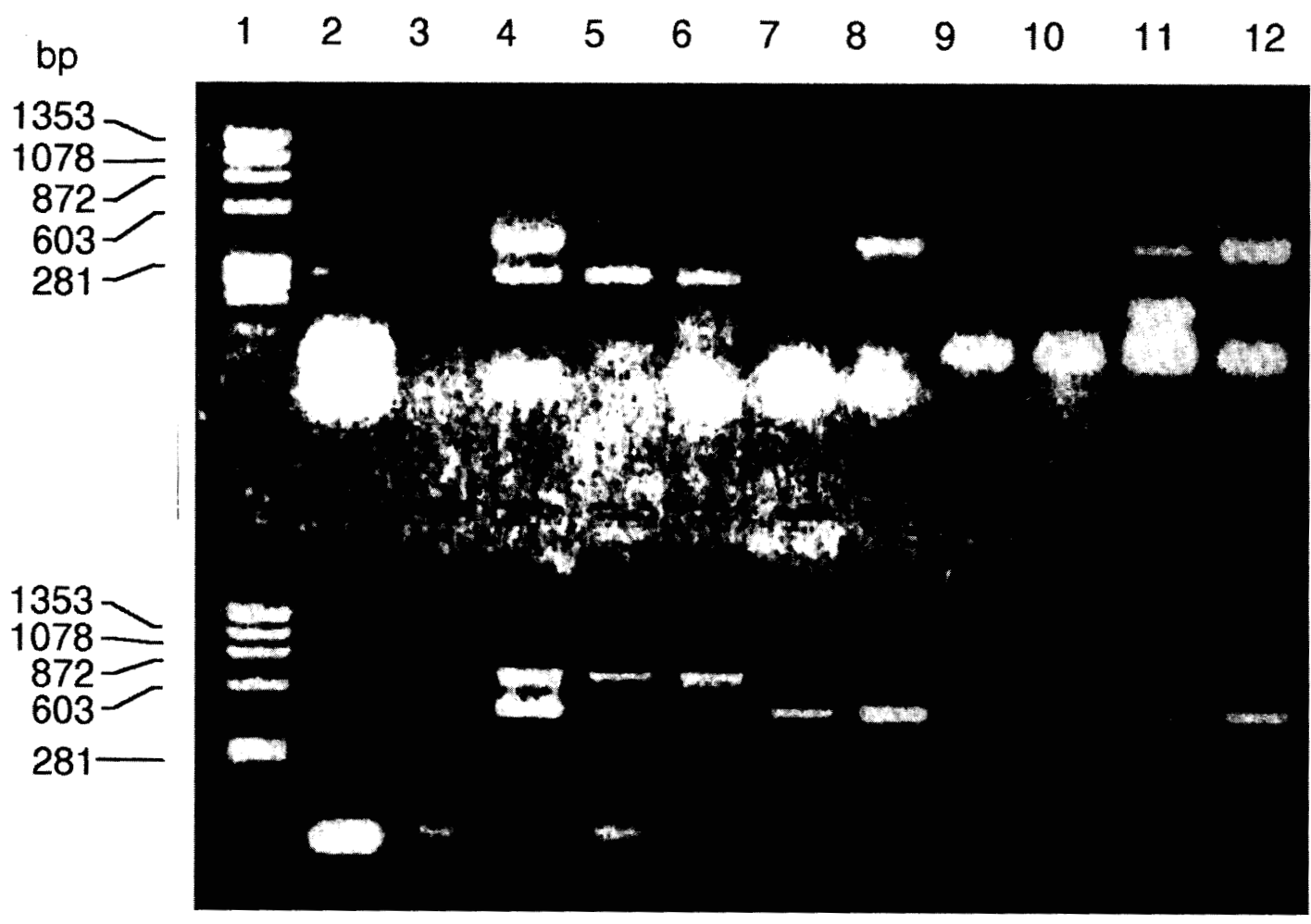

Fig. 1. Agarose gel electrophoresis of amplified HPV DNA fragments from genomic DNA of cervical cells following PCR. Upper row (HPV 6 and 11): lane 1, size marker, Phi-X174/HaelII (500 ng); 2, negative control; 3, blank; 4, positive controls of HPV 6 (263 bp) and 11 (406 bp) DNA; 5-12, samples. Lower row (HPV 16 and 18): lane 1, size marker, Phi-X174/HaelII (500 ng); 2, negative control; 3, blank; 4, positive controls of HPV 16 (694 pb) and 18 (472 bp) DNA; 5-12, samples.

\section{Results}

The prevalence of multiple HPV infections in patients with normal cervices, low-grade SILs, high-grade SILs and cervical carcinomas was $22.2 \%$ (16 of 72 ), $61.8 \%$ (34 of 55), 41.5\% (22 of 53) and 21.3\% (10 of 47), respectively. The prevalence of a single-type infection in patients with normal cervices, low-grade SILs, high-

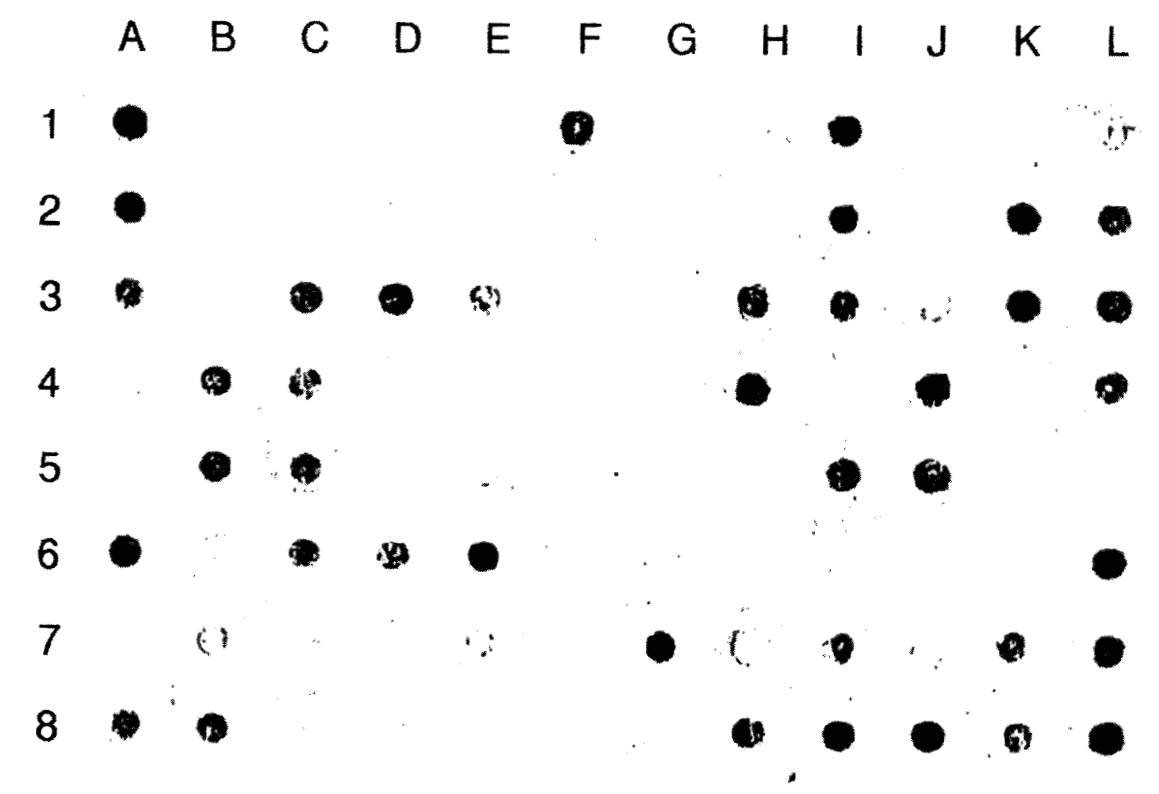

Fig. 2. Dot-blot hybridisation of the PCR products with digoxigenin-labelled HPV DNA probes [14]. A, 1-5, positive controls for hybridisation, i.e., purified HPV DNA $1 \mathrm{ng}, 100 \mathrm{pg}, 10 \mathrm{pg}, 1 \mathrm{pg}, 0.1 \mathrm{pg}$, respectively; $\mathbf{A}, \mathbf{6 , 7}$, the products of positive and negative PCR controls, respectively; the others are samples. 
grade SILs and cervical carcinomas was $36.1 \%$ (26 of 72 ), $21.8 \%$ (12 of 55), 30.2\% (16 of 53) and $61.7 \%$ (29 of 47), respectively, whereas in those without infection the prevalence was $41.7 \%$ (30 of 72 ), $16.4 \%$ ( 9 of 55 ), $28.3 \%$ (15 of 53 ) and $17 \%$ ( 8 of 47 ) respectively. HPV $16 / 11$ or $16 / 18$ were common combinations in multiple infections. The prevalence of a single-type HPV 16 infection in patients with normal cervices, low-grade SILs, high-grade SILs and cervical carcinomas was $8.3 \%, 10.9 \%, 22.6 \%$ and $46.8 \%$, respectively, whereas the prevalence of a single-type HPV 11 infection was $23.6 \%, 10.9 \%, 7.5 \%$ and $4.3 \%$, respectively.

The prevalence of single-type, negative and multiple HPV infections varied significantly among the four groups of patients $\left(\chi^{2}=38.8, \mathrm{p}<0.0001\right)$. Multiple HPV infections were most frequently seen in patients with low-grade SILs $(61.8 \%)$. This prevalence decreased with increasing severity of cervical neoplasia $(p<0.0001)$. In contrast, single-type HPV infection was most commonly observed in patients with cervical carcinomas $(61.7 \%)$, while the prevalence decreased with decreasing severity of cervical neoplasia $(p<0.001)$. It was noteworthy that HPV 16 was the predominant single-type infection in patients with cervical carcinoma and the prevalence of single-type HPV 16 infection decreased steadily with decreasing severity of cervical neoplasia $(p<0.0001)$. In contrast, HPV 11 was the predominant single-type infection in patients with normal cervices and the prevalence of single-type HPV 11 infection decreased with increasing severity of cervical neoplasia $(p<0.01)$. The prevalence of single-type, negative and multiple HPV infections based on individual case are summarised in Table 2.

The prevalence of HPV 6 infection, regardless of single of multiple status, in patients with normal cervices, low-grade SILs, high-grade SILs and cervical carcinomas was $6.9 \%, 14.5 \%, 15.1 \%$ and $10.6 \%$, respectively, while that of HPV 18 was $16.7 \%, 36.4 \%$, $26.4 \%$ and $21.3 \%$, respectively. The prevalence of HPV 16 infection in patients with various grades of cervical neoplasia ranged from $63 \%$ to $69.1 \%$. These were much greater than that $(23.6 \%)$ of patients with normal cervices $(p<0.0001)$. HPV 11 infection was most frequently $(50.9 \%)$ seen in patients with lowgrade SILs, and the prevalence decreased with increasing severity of cervical neoplasia $(p<0.001)$. Generally, those with increasing severity of cervical neoplasia were more likely to be positive by first round PCR, and especially for HPV 16 infection $(p<0.0001)$. The prevalences of each HPV infection regardless of single or multiple status are summarised in Table 3.

\section{Discussion}

Women with cervical neoplasia generally have HPV infection more frequently than those with normal cervices. In the present work, the prevalence of HPV $6,11,16$ or 18 infection in patients with various grades of cervical neoplasia $(71.7-83.6 \%)$ was greater than that $(58.3 \%)$ in patients with normal cervices $(\mathrm{p}<0.01)$ (Table 2$)$. The prevalence $(58.3 \%)$ of HPV DNA in samples of normal cervices examined by PCR is relatively higher in the present work but is still within the range $5-70 \%$ reported previously and is generally greater than those obtained by other conventional hybridisation methods $[17,20,21]$. Theoretically, the odds ratio of HPV infection relating to cervical cancer becomes small when the prevalence of HPV infection in normal patients rises. In other words, the correlations of HPV infection with disease outcome weakens when disproportionately more normal controls are diagnosed to be HPV positive by a more sensitive detection method such as PCR [22].

Table 2. Prevalence of single-type and multiple HPV infections in patients with various grade of cervical neoplasia

\begin{tabular}{|c|c|c|c|c|}
\hline \multirow[b]{2}{*}{ HPV infection } & \multicolumn{4}{|c|}{ Number $(\%)$ of patients with } \\
\hline & Normal cervix & Low-grade SIL & High-grade SIL & Cervical cancer \\
\hline Negative* $^{*}$ & $30(41.7)$ & $9(16.4)$ & $15(28.3)$ & $8(17.0)$ \\
\hline Positive* & $42(58.3)$ & $46(83.6)$ & $38(71.7)$ & $39(83.0)$ \\
\hline Single $\mathrm{e}^{\dagger}$ & $26(36.1)$ & $12(21.8)$ & $16(30.2)$ & $29(61.7)$ \\
\hline type 6 & $1(1.4)$ & 0 & 0 & $2(4.3)$ \\
\hline type $11^{*}$ & $17(23.6)$ & $6(10.9)$ & $4(7.5)$ & $2(4.3)$ \\
\hline type $16^{\ddagger}$ & $6(8.3)$ & $6(10.9)$ & $12(22.6)$ & $22(46.8)$ \\
\hline type 18 & $2(2.8)$ & 0 & 0 & $3(6.4)$ \\
\hline Multiple + & $16(22.2)$ & $34(61.8)$ & $22(41.5)$ & $10(21.3)$ \\
\hline 2 types & $13(18.1)$ & $22(40.0)$ & $12(22.6)$ & $8(17.0)$ \\
\hline $16 \& 18$ & 4 & 10 & 6 & 4 \\
\hline $16 \& 11$ & 4 & 10 & 6 & 3 \\
\hline others & 5 & 2 & 0 & 1 \\
\hline 3 types & $2(2.8)$ & $10(18.2)$ & $10(18.9)$ & $2(4.3)$ \\
\hline 4 types & $1(1.4)$ & $2(3.6)$ & 0 & 0 \\
\hline Total & 72 & 55 & 53 & 47 \\
\hline
\end{tabular}

Significant difference of the prevalence rates among various groups of patients, ${ }^{*} p<0.01,{ }^{\dagger} p<0.001,{ }^{*} p<0.0001$. SIL, squamous intraepithelial lesion. 
Table 3. Prevalence of each HPV infection, regardless of single-type or multiple status

\begin{tabular}{|c|c|c|c|c|c|}
\hline \multirow[b]{2}{*}{ HPV infection } & \multirow[b]{2}{*}{ Step of PCR } & \multicolumn{4}{|c|}{ Number (\%) of patients with } \\
\hline & & Normal cervix & Low-grade SIL & High-grade SIL & Cervical cancer \\
\hline HPV 6 & $\begin{array}{l}\text { a) PCR-1 } \\
\text { b) PCR-2 } \\
\text { a)/b })^{\S}\end{array}$ & $\begin{array}{ll}1 & (1.4) \\
5 & (6.9) \\
& (20)\end{array}$ & $\begin{array}{ll}2 & (3.6) \\
8 & (14.5) \\
& (25)\end{array}$ & $\begin{array}{ll}2 & (3.8) \\
8 & (15.1) \\
& (25)\end{array}$ & $\begin{array}{ll}4 & (8.5) \\
5 & (10.6) \\
& (80)\end{array}$ \\
\hline HPV 11 & $\begin{array}{l}\text { a) } \mathrm{PCR}-1 \\
\text { b) } \mathrm{PCR}-2 \dagger \\
\text { a) } / \mathrm{b})^{\S}\end{array}$ & $\begin{aligned} 21 & (29.2) \\
28 & (38.9) \\
& (75)\end{aligned}$ & $\begin{aligned} 12 & (21.8) \\
28 & (50.9) \\
& (43)\end{aligned}$ & $\begin{aligned} 8 & (15.1) \\
14 & (26.4) \\
& (57)\end{aligned}$ & $\begin{array}{cc}5 & (10.6) \\
5 & (10.6) \\
& (100)\end{array}$ \\
\hline HPV 16 & $\begin{array}{l}\text { a) PCR-1 } \\
\text { b) PCR-2 } \\
\text { a) }(b)^{\ddagger \S}\end{array}$ & $\begin{aligned} 6 & (8.3) \\
17 & (23.6) \\
& (35)\end{aligned}$ & $\begin{aligned} 6 & (10.9) \\
38 & (69.1) \\
& (16)\end{aligned}$ & $\begin{array}{c}14(26.4) \\
34(63.0) \\
\quad(41)\end{array}$ & $\begin{array}{cl}27 & (57.4) \\
31 & (66.0) \\
& (87)\end{array}$ \\
\hline HPV 18 & $\begin{array}{l}\text { a) PCR-1 } \\
\text { b) PCR-2 } \\
\text { a) } / \text { b })^{\S}\end{array}$ & $\begin{array}{cl}10 & (13.8) \\
12 & (16.7) \\
& (83)\end{array}$ & $\begin{array}{cc}18 & (32.7) \\
20 & (36.4) \\
& (90)\end{array}$ & $\begin{array}{c}12(22.6) \\
14(26.4) \\
\quad(86)\end{array}$ & $\begin{array}{rr}10 & (21.3) \\
10 & (21.3) \\
& (100)\end{array}$ \\
\hline
\end{tabular}

SIL, squamous intraepithelial lesion; PCR-1, positive at the end of the first-step PCR; PCR-2, positive by two steps of PCR.

Significant difference of the prevalence rates among various groups of patients, ${ }^{\dagger} p<0.001,{ }^{\ddagger} p<0.0001$.

SProportion of positivity by the first-step PCR.

Lauricella-Lefebvre and colleagues screened cervical smears for HPV types 6, 11, 16 and 18 infections in 450 patients involved in a clinical follow-up of cervical HPV infection and found that HPV 16 was the most common single-type infection (25.4\%) [23]. In the present work, the prevalence of single-type HPV infection $(61.7 \%)$ was much greater in patients with cervical carcinoma than that $(21.8 \%-36.1 \%)$ in other patient groups $(p<0.001)$. The predominance of single-type HPV 16 infection in patients with cervical carcinoma may account for this discrepancy. The prevalence of single-type HPV 16 infection increased steadily from $8.3 \%$ in patients with normal cervices to $46.8 \%$ in those with cervical carcinoma ( $p<0.0001$ ), which supports a role for HPV 16 in the pathogenesis of cervical cancer. On the other hand, the prevalence of HPV 11 infection decreased with increasing severity of cervical lesions $(p<0.01)$, which suggests a benign nature of HPV 11 infection. The trend of change for those infected with HPV 6 or 18 was not so clear-cut in the present work.

A further finding of the present study was the detection of a large number of multiple HPV infections in patients with low-grade SILs. Simultaneous infection with more than one HPV type has not been reported frequently. Hinrichs and colleagues demonstrated two types of HPVs occupying distinct and non-overlapping foci within the lesions by in situ hybridisation [24]. The reported prevalence of multiple HPV infections has varied greatly in different studies $[23,25]$. In the present study, the prevalence of multiple HPV infections seems to vary with the severity of cervical lesions, being $61.8 \%$ for patients with low-grade SILs (representing $73.9 \%$ of positive cases), $41.5 \%$ for patients with high-grade SILs ( $57.9 \%$ of positive cases), and $21.3 \%$ for those with cervical carcinomas $(25.6 \%$ of positive cases $)$ $(p<0.0001)$. The trend changing from predominant multiple HPV infections in patients with low-grade SILs to predominant single-type infection in those with cervical carcinomas is worth further examination. The resultant interactions of different types of HPV during the progression of cervical neoplasia or the emergence of a dominant clone of cervical cancer cells may be responsible for this pattern of change. This finding also indicates that low-grade SILs are relatively heterogeneous with regard to associated HPV types, while high-grade SILs are relatively more homogeneous with regard to associated HPV types [26].

The prevalence of multiple HPV infections varies among different detection methods. Theoretically, more HPVs present at low copy number could be detected when a more sensitive method is applied; thus, the frequency of detection of multiple infections will be higher. In fact, multiple infections are more commonly observed with PCR methods than when DNA hybridisation techniques are used $[2,17,27]$. Moreover, the difference in sensitivity between the one-step and two steps of PCR is evident [14]. The copy numbers of HPV DNA in samples positive for amplification at the end of the first-step PCR are generally larger than those positive only following two steps of PCR. In the present study, the prevalence of HPV 16 infection detected by two steps of PCR began to rise abruptly in patients with low-grade SILs (69.1\% versus $23.6 \%$ in those with normal cervices), while the prevalence of HPV 16 by the first-step PCR rose gradually along with the severity of cervical neoplasia ( $\mathrm{p}<0.0001$ ) (Table 3 ). These findings might suggest that most cases of cervical dysplasia progressed with the acquisition of a low copy-number of the 'oncogenic' HPV 16 DNA [28], while the accumulation of large copy-number of HPV 16 DNA 
develops later in more advanced lesions. However, whether this trend of change in virus status is the cause or the result of the malignant process remains to be clarified. It is also difficult to know what contribution is made by low-risk types $6 / 11$ in association with high risk types $16 / 18$ in cervical cancer and what is the contribution of any of the different types in dysplasia. Perhaps these HPVs might just happen to be associated with cervical neoplasia.

Nuovo and colleagues reported that infection by one type is rarely associated with concurrent active infection by a second HPV type [2]. It is possible that an existing HPV infection may inhibit or limit the replication of other types of HPV, or the presence of certain HPV DNA, especially of large copy number, may interfere and prevent other types of HPV DNA from being detected by PCR $[24,29]$. PCR with typespecific instead of consensus primers may prevent this technical interference. The other important factor to account for the finding of a predominance of singletype HPV infection in cervical carcinomas may be related to a sampling bias. Because well-developed carcinomas usually originated and grew monoclonally, tests on samples derived from 'monoclonal' cancer cells may lead to a higher likelihood of obtaining a single HPV type. Moreover, in the present work, patients with cervical carcinomas were significantly older and had higher prevalence of HPV 16 infection than other groups of patients. Prevalence of HPV in cytomorphologically normal cervical smears is agedependent [30]. Generally, increasing age is significantly associated with a lower prevalence of HPV infection [31]. However, infection with HPV types 16 and 18 is not related to the age of patients with cervical cancer $[32,33]$. Therefore, age appears to be a potentially confounding variable but should not be an exclusive and definitive factor [34].

The authors thank the National Science Council of Taiwan for financial support.

\section{References}

1. de Villiers E-M. Heterogeneity of the human papillomavirus group. J Virol 1989; 63: 4898-4903.

2. Nuovo GJ, Darfler MM, Impraim CC, Bromley SE. Occurrence of multiple types of human papillomavirus in genital tract lesions. Analysis by in situ hybridization and the polymerase chain reaction. Am J Pathol 1991; 138: 53-58.

3. Gissmann L, Wolnik L, Ikenberg H, Koldovsky U, Schnürch HG, zur Hausen H. Human papillomavirus types 6 and 11 DNA sequences in genital and laryngeal papillomas and in some cervical cancers. Proc Natl Acad Sci USA 1983; 80; $560-563$.

4. Dürst M, Gissmann L, Ikenberg $H$, zur Hausen $H$. A papillomavirus DNA from a cervical carcinoma and its prevalence in cancer biospy samples from different geographic regions. Proc Natl Acad Sci USA 1983; 80: 3812-3815.

5. Boshart M, Gissmann L, Ikenberg H, Kleinheinz A, Scheurlen W, zur Hausen $\mathrm{H}$. A new type of papillomavirus DNA, its presence in genital cancer biopsies and in cell lines derived from cervical cancer. $E M B O J 1984 ; 3$ : $1151-1157$.
6. Chang DY, Hsieh CY, Hsieh HC. Malignant transformation of condyloma acuminatum: report of a case. $J$ Formos Med Assoc 1990; 89: 475-478.

7. Tabbara S, Saleh AD, Andersen WA, Barber SR, Taylor PT, Crum $\mathrm{CP}$. The Bethesda classification for squamous intraepithelial lesions: histologic, cytologic and viral correlates. Obstet Gynecol 1992; 79: 338-346.

8. Birley HD, Hart CA, Stacey SN. Human papillomaviruses and the genital tract: old virus, new developments. $J$ Med Microbiol 1995; 43: 81-84.

9. Hsieh CY, Lee SC, Huang SC. Presence and expression of human papillomavirus types 16 and 18 DNA sequences in cervical carcinomas. Asia Oceania J Obstet Gynaecol 1988; $14 ; 87-95$.

10. Lim Tan SK, Yoshikawa H, Sng IT et al. Human papillomavirus in dysplasia and carcinoma of the cervix in Singapore. Pathology 1988; 20: 317-319.

11. Demeter T, Kulski JK, Sterrett GF, Pixley EC. Detection of DNA of human papillomavirus types $6 / 11$ and $16 / 18$ in cell scrapings of the uterine cervix by filter in situ hybridisation. Correlation with cytology, colposcopy and histology. Eur $J$ Epidemiol 1987; 3 404-413.

12. Lorincz AT, Reid R, Jenson AB, Greenberg MD, Lancaster W, Kurman RJ. Human papillomavirus infection of the cervix: relative risk associations of 15 common anogenital types. Obstet Gynecol 1992; 79: 328-337.

13. Saiki RK, Gelfand DH, Stoffel $\mathrm{S}$ et al. Primer-directed enzymatic amplification of DNA with a thermostable DNA polymerase. Science 1988; 239: 487-491.

14. Chang DY, Hsieh CY, Chen RJ, Lee SC, Huang SC. Comparison of detection of human papillomavirsus 16 DNA in cervical carcinoma tissues by Southern blot hybridisation and nested polymerase chain reaction. J Med Microbiol 1995; 43: $430-435$.

15. Evander M, Edlund K, Bodén E et al. Comparison of a onestep and a two-step polymerase chain reaction with degenerate general primers in a population-based study of human papillomavirus infection in young Swedish women. $J$ Clin Microbiol 1992; 30: 987-992.

16. Ward P, Parry GN, Yule R, Coleman DV, Malcolm AD Comparison between the polymerase chain reaction and slot blot hybridization for the detection of HPV sequences in cervical scrapes. Cytopathology 1990; 1: 19-23.

17. Melchers W, van den Brule A, Walboomers $\mathbf{J}$ et al. Increased detection rate of human papillomavirus in cervical scrapes by the polymerase chain reaction as compared to modified FISH and southern-blot analysis. J Med Virol 1989; 27: 329-335.

18. Sambrook J, Fritsch EF, Maniatis T. Molecular cloning. A laboratory manual. Cold Spring Harbor, NY, Cold Spring Harbor Laboratory Press. 1989.

19. Cone RW, Minson AC, Smith MR, McDougall JK. Conservation of HPV-16 E6/E7 ORF sequences in a cervical carcinoma. $J$ Med Virol 1992; 37: 99-107.

20. Young LS, Bevan IS, Johnson MA et al. The polymerase chain reaction: a new epidemiological tool for investigating cervical human papillomavirus infection. $B M J 1989 ; 298 ; 14-18$.

21. Syrjänen S, Saastamoinen J, Chang $F$, Ji $H$, Syrjänen $K$. Colposcopy, punch biospy, in situ DNA hybridization, and the polymerase chain reaction in searching for genital human papillomavirus (HPV) infections in women with normal PAP smears. J Med Virol 1990; 31: 259-266.

22. Kaldor JM. Measurement error in epidemiological studies of human papillomarvirus and cancer. IARC Sci Publ 1989; (94) 125-133.

23. Lauricella-Lefebvre M-A, Piette J, Lifrange E, Lambotte R, Gerard P, Rentier B. High rate of multiple genital HPV infections detected by DNA hybridization. J Med Virol 1992; 36: $265-270$.

24. Hinrichs S, Smith L, Ghazvini S, Kirvern K, Palladino $H$, Spaulding D. Multiple HPV infection: microanatomy by in situ hybridization and immunohistochemistry. Mod Pathol 1992; 5: 257-261.

25. Griffin NR, Bevan IS, Lewis FA, Wells M, Young LS Demonstration of multiple HPV types in normal cervix and in cervical squamous cell carcinoma using the polymerase chain reaction on paraffin wax embedded material. $J$ Clin Pathol 1990; 43: 52-56.

26. Lungu O, Sun XW, Felix J, Richart RM, Silverstein S, Wright TCJ. Relationship of human papillomavirus type to grade of 
cervical intraepithelial neoplasia. JAMA 1992; 267: 2493 2496.

27. Reid R, Greenberg M, Jenson $A B$ et al. Sexually transmitted papillomaviral infections. 1. The anatomic distribution and pathologic grade of neoplastic lesions associated with different viral types. Am J Obstet Gynecol 1987; 156: 212-222.

28. Iwasaka T, Yokoyama M, Hayashi Y, Sugimori H. Human papillomavirus 16 and 18 DNA can solely induce oncogenic transformation of mammalian cells in primary culture. Acto Obstet Gynecol Scand 1993; 72: 81-86.

29. Tucker RA, Johnson PR, Reeves WC, Icenogle JP. Using the polymerase chain reaction to genotype human papillomavirus DNAs in samples containing multiple HPVs may produce inaccurate results. J Virol Methods 1993; 43: 32l-333.

30. Melkert PW, Hopman E, van den Brule AJ et al. Prevalence of HPV in cytomorphologically normal cervical smears, as determined by the polymerase chain reaction, is agedependent. Int J Cancer 1993; 53: 919-923.
31. Figueroa JP, Ward E, Luthi TE, Vermund SH, Brathwaite AR, Burk RD. Prevalence of human papillomavirus among STD clinic attenders in Jamaica: association of younger age and increased sexual activity. Sex Transm Dis 1995; 22: 114-118.

32. Sebbelov AM, Kjorstad KE, Abeler VM, Norrild B. The prevalence of human papillomavirus type 16 and 18 DNA in cervical cancer in different age groups: a study on the incidental cases of cervical cancer in Norway in 1983. Gynecol Oncol 1991; 41: 141-148.

33. de Roda Husman AM, Walboomers JMM, Hopman E et al. HPV prevalence in cytomorphologically normal cervical scrapes of pregnant women as determined by PCR: the agerelated pattern. J Med Virol 1995; 46: 97-102.

34. Syrjanen K, Yliskoski M, Kataja V et al. Prevalence of genital human papillomavirus infections in a mass-screened Finnish female population aged $20-65$ years. Int J STD AIDS 1990; 1: $410-415$. 